\title{
BIOSIMILAR MEDICINE PRICE ANALYSIS IN BRAZIL: THE ANTIRHEUMATIC CASE
}

\author{
GABRIELA BITTENCOURT GONZALEZ MOSEGUI ${ }^{*}$, FERNANDO ANTOÑANZAS VILLAR², \\ CID MANSO DE MELLO VIANNA ${ }^{3}$, PAULA GARCIA ROJAS ${ }^{2}$
}

\begin{abstract}
${ }^{1}$ Community Health Institute, Fluminense Federal University, Rio de Janeiro, Brazil. ${ }^{2}$ Department of Economy and Company, Economy Faculty, University of La Rioja, Logroño, La Rioja, Spain. ${ }^{3}$ Social Medicine Institute, Rio de Janeiro State University, Rio de Janeiro, Brazil. Email: gabrielamosegui@uol.com.br
\end{abstract}

Received: 20 May 2020, Revised and Accepted: 30 June 2020

ABSTRACT

Objective: The introduction of biosimilar medicines in markets can bring savings to health systems, expanding the population's access to various treatments. This study aims to analyze the price competition of biological agents and their biosimilars in Brazil within the scope of rheumatoid arthritis.

Methods: Prices for 14 presentations of original and biosimilar medicines were analyzed from January 2003 to October 2019 in Brazil. Prices were taken from official lists and were noted since launch and during the later trading period. Prices were converted to United States dollars and adjusted for inflation for the 2003 base year.

Results: In Brazil, during this review period, prices of biopharmaceuticals decreased in real values, reaching up to a $50 \%$ reduction. The introduction of biosimilars did not affect the price sharing of biological medicines.

Conclusion: Biosimilar antirheumatics do not yet have a significant impact on the price of biologics marketed in Brazil. A change in this scenario is expected in the medium and long term.

Keywords: Biological products, Drug price, Antirheumatic agents, Access to essential medicines, Health technologies.

(c) 2020 The Authors. Published by Innovare Academic Sciences Pvt Ltd. This is an open access article under the CC BY license (http://creativecommons. org/licenses/by/4. 0/) DOI: http://dx.doi.org/10.22159/ajpcr.2020.v13i9.38641

\section{INTRODUCTION}

Biopharmaceutical or biological agents are complex molecules of high molecular mass obtained from tissues of animal origin or biotechnological procedures carried out under controlled conditions. The intended biological activity depends on strictly controlled modifications made to the molecules [1-3].

Biosimilars are biological products equivalent in quality, effectiveness, and safety to an original biological medicine called the reference product $[4,5]$. Their goal is to increase access to biological therapy, reducing costs $[1,6]$. It should be noted that there are high risks of research and development as well as high costs in their production [7].

The introduction of biological drugs in the treatment of rheumatic diseases such as rheumatoid arthritis (RA) has changed the lives of many patients in the past 20 years $[8,9]$. They are a new generation of drugs that are effective and expensive. While actively slowing the progression of disease symptoms, they can represent an important economic burden for individuals and health systems [3,4].

European health systems finance biosimilars with average prices up to $30 \%$ lower than reference products [4]. Daily treatment prices have also decreased, driven by a greater degree of competition. In the United States (US), legal and patent issues prevent biosimilars from entering the market faster [10], although their prices are lower than those of the original medicines [11].

In Latin America, the increase in the use of this class of drugs should boost competition, benefiting governments, prescribers, and users of the health system, with both lower prices and greater access to treatments [12]. For this block, there is a concentration of regulatory studies, but few price analyses [7,13-15]. In Colombia, although there is some information about price, there is little systematization and there is no classification or details about this drug class [7]. In Brazil, although biological products represent $22 \%$ of the total market turnover, they sold only 3.8\% of pharmaceutical presentations in 2017. The absorption of these products took place mainly between 2016 and 2017, with the federal government responsible for more than $50 \%$ of purchases seeking to expand and ensure the population's access to these inputs [3].

As little is known about the price evolution of these products and considering that RA is a disease that employs biological agents in patients who do not respond to first-line therapy, the objective of this study is to analyze the effects of price competition between agents and their biosimilars in Brazil in the scope of RA.

\section{METHODS}

The records and prices of antirheumatics of biological origin and their biosimilars were analyzed. The registration information was taken from the page of the National Health Surveillance Agency (Anvisa) [16]. The Clinical Protocol and Therapeutic Guidelines for the treatment of RA were reviewed, looking for other therapeutic possibilities that had not been captured to complement the registration data [17].

A sample of 14 antirheumatic biological agents was defined for the treatment of RA, 10 original products and 4 biosimilars, from the list of launches between 2003 and 2019. These products were listed by the year of manufacture, pharmaceutical form(s), and packaging. The unit of analysis of the study was the product, in equal concentrations and packaging. Any drug association was excluded from the study.

The year of publication of the authorization to market the biosimilar guided the monitoring of price developments in the following periods. The prices of the first biosimilar and of its respective original 
biopharmaceutical were taken at the following times: In its first commercialization; and 1, 2, and 3 years after launch when possible. Some drugs had their prices monitored for 4 years and others for 1 or 2 years, or only their initial prices were compared. The price of the packaging with the largest quantity or cheapest presentation was taken.

Reference wholesale prices were used as the basis for the survey, referring to the Anvisa page, in the price lists of the Medicines Market Regulation Chamber (CMED), starting in 2003 [18]. The standard established was the maximum consumer price (price monitoring cell), referring to $18 \%$ of the tax on the circulation of goods and provision of services.

Real prices were estimated, starting in the base year of 2003, using the Wholesale Price Index - Global Supply (IPA-OG) - Industrial products [19]. All prices were standardized/converted into US dollars, using the exchange rates of the Central Bank of Brazil [20], year by year.

This study did not require approval from the institutional review board or informed consent, as it is based on public data and does not involve patient records.

\section{RESULTS}

The evolution of prices between 2003 and 2019 in dollars and in reais in nominal values and in 2003 is shown in Fig. 1 .

The prices of original biological medicines have changed in real terms, mainly in the last decade. Most of these prices fell by approximately $20 \%$. Adalimumab, certolizumab pegol, etanercept, golimumab, infliximab, and tocilizumab had their prices reduced by $12.0 \%, 20.8 \%, 18.8 \%$, $20.8 \%, 15.0 \%$, and $19.0 \%$, respectively. Exceptions were abatacept, with a decrease of $38.9 \%$; rituximab, with a decrease of $49.6 \%$; and tofacitinib, with a decrease of $2.3 \%$, partly due to its presence in the market since 2015 .

The drugs sold before 2008 were those that had the largest drop: adalimumab - 27.4\%; etanercept - 53.6\%; and rituximab - 55.0\%. However, with similar price decreases, the last two had different trajectories. The reduction in the price of etanercept was $43 \%$ until 2008 , while the price of rituximab fell only $15 \%$ in the same period. In 2009 , the paths are reversed, with the first decreasing by approximately $10 \%$ and the second decreasing by $57 \%$.

The appearance of golimumab and certolizumab pegol as of 2012 created at least four price levels: Three for biologicals and one for biosimilars. One of these price levels, at 2003 prices, up to a thousand reais, includes certolizumab pegol, abatacept, tocilizumab, and rituximab. Another price level, up to approximately two thousand reais, includes etanercept, golimumab, and tocilizumab. Tofacitinib and adalimumab remain at a higher level, with values above three thousand reais. The last group includes biosimilars. The average prices for these groups are $\mathrm{R} \$ 895.00, \mathrm{R} \$ 2,100.00, \mathrm{R} \$ 3,700.00$, and $\mathrm{R} \$$ 1,500.00 (Fig. 2).

The influence of biosimilars on the prices of original drugs is not clear. In addition to the short time of commercialization, from 2016 onward, the downward trend in the values practiced by biologicals has not changed. Even though their prices are lower than their direct substitutes, they have higher levels than the product group of up to a thousand reais.

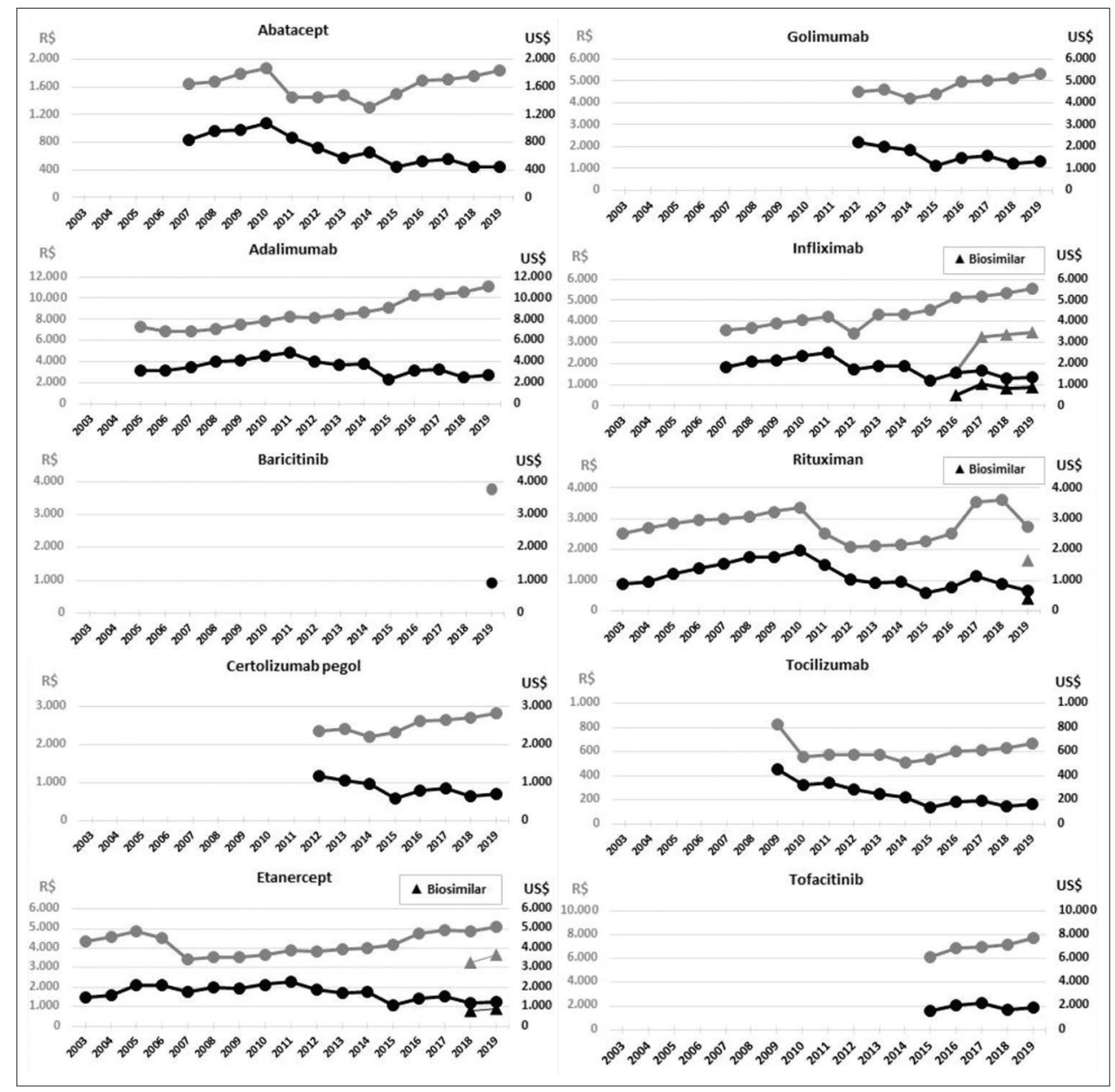

Fig. 1: Prices of biological and biosimilar medicines for rheumatoid arthritis in Brazil, in reais and dollars, from 2003 to 2019. Source: Own elaboration, based on the prices of the CMED [17] 


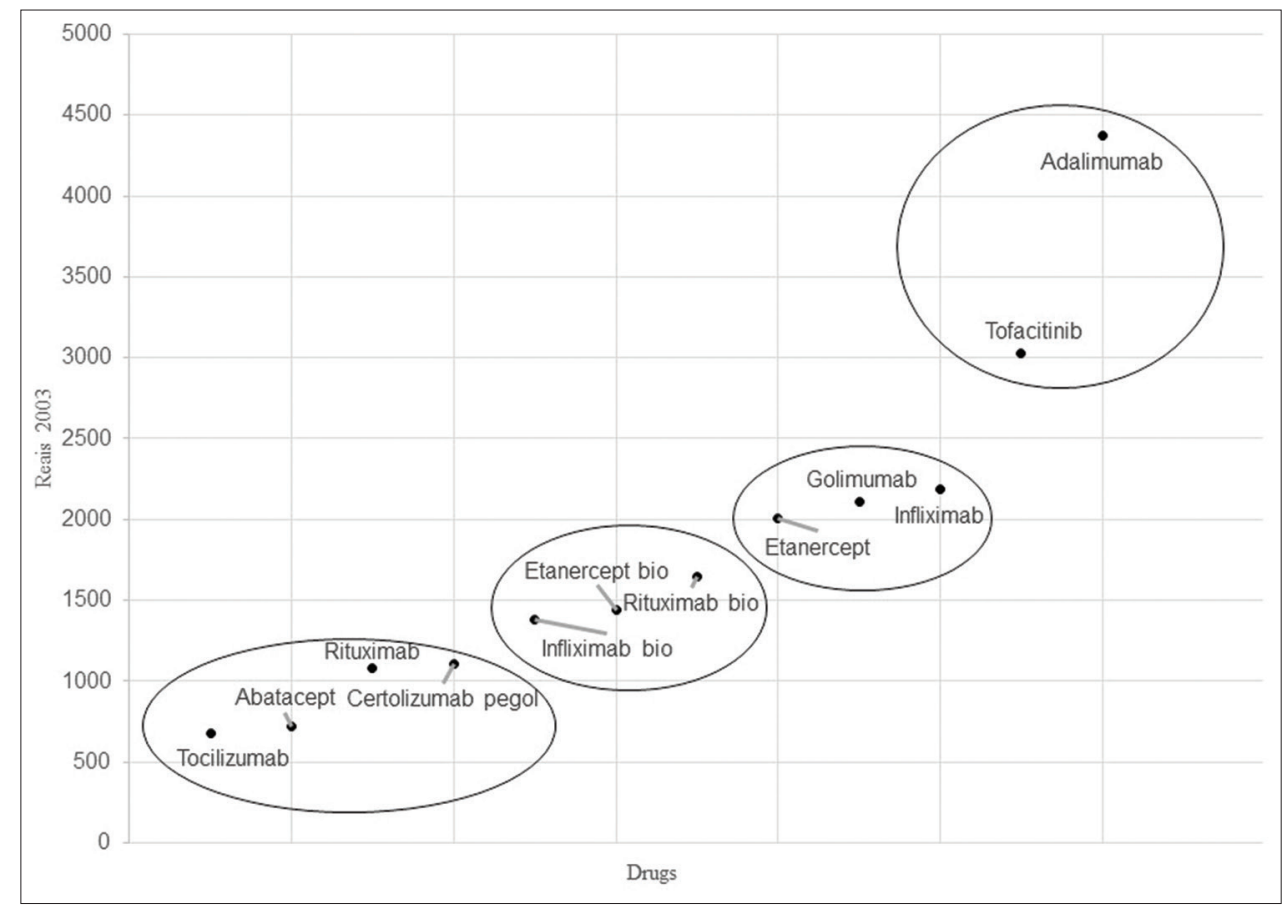

Fig. 2 : Distribution of medicines by price group. Source: Own elaboration

\section{DISCUSSION}

In Brazil, there were 10 approved biological medicines in the analyzed period, which were divided into three price groups. Four below one thousand reais, four at the level of two thousand reais and two above three thousand reais. The biosimilars were distributed in a segment with values of approximately fifteen hundred reais. It was decided to use the reference prices for retail indicated by the federal government, even though we were aware of possible disparities between the fixed values and those paid by the public administration in bidding processes [21]. On the one hand, Brazil has a complex and costly tax model for medicines; on the other hand, despite the information on how public resources are used, having gained more transparency in recent years, they need even more transparency so that we understand how they are used as an instrument of social control [22].

The short authorization period for the commercialization of biosimilar agents for RA in Brazil, of almost 2 years for etanercept, four for infliximab and approximately 1 year for rituximab, does not allow an in-depth analysis. Despite this, there seems to be no evidence, at least in the short term, that there will be a reduction in the price of the original biologicals due to biosimilars. This is because, for the group of drugs below a thousand reais, there will be no impact. For the group based on two thousand reais, there should also be no competitive price, since the relationship with biosimilars is already within the expected reduction margin.

Adalimumab and tofacitinib, which have prices above three thousand reais, would remain. However, it does not seem feasible to expect a significant drop. The two drugs already face competition from other biologicals, with lower prices, without their market values having decreased. Analogous to the insertion of generics that increased the offer of products with lower prices without decreasing the reference prices [23], the biosimilars seem to be moving in the same direction.

Therapies based on biological products have had a significant impact on several diseases in which medical needs are not satisfactorily met. In contrast, the high cost of treatment with these drugs constitutes an effective barrier to access in several parts of the world, including in more developed countries [24].
Brazil seems to behave in contrast to the international scenario, where the impact of the entry of biosimilars has been observed. In Spain, biosimilars are priced 30\% less than the original biopharmaceuticals, as agreed upon by Decree [8,25]. German social insurance receives discounts of $10 \%$ for medicines with the same manufacturing process. In Italy, prices initially fell between 15 and 22\%, and today, this decrease has been progressive to encourage access to biosimilars [8].

Nevertheless, it is hoped that these products, as well as generic drugs, can reduce the cost of medical intervention in various regions of the world as patents for biologicals expire [26,27]. However, unlike generics, which were introduced at prices up to $40 \%$ lower than the originals, reaching over time up to $68 \%$ [23], some authors expect that the price reductions of biosimilars will not be greater than $30 \%[28,29]$.

\section{CONCLUSION}

The main objective of this study was to analyze the extent of the price difference between the biological agents used in the treatment of RA in Brazil and its biosimilars, discussing the possible effects of competition between them. Biological medicines showed the highest growth rate, $37.5 \%$ between 2015 and 2017 , accounting for $22 \%$ of total sales in the last year. In contrast, biosimilars were in the drug class with the lowest number of units sold (168.1 million reais) [3,30].

The prices of all original organic products have been decreasing steadily in real values since 2003. This drop was greater than $50 \%$ for some of them. The structure of the Brazilian market was designed in the form of three groups of price levels. It would be important to observe carefully, as more drugs are introduced in the market, the configuration of the competitive process, seeking to foresee behaviors and trends, as it happens in Europe.

In the past 4 years, biosimilar medicines obtained their registration with Anvisa and started to be commercialized, but their impact is still unknown. Although the period is short for definitive evaluation, this market seems to follow what has happened in generics. Increased supply of products with less expensive prices has a low effect on the price level practiced for reference products. The optimism, both in international and Brazilian literature, that biosimilars may cause a 
decrease in the values of innovative biologicals seems to have no basis for support, at least in the short term.

\section{ACKNOWLEDGMENTS}

We would like to thank Carolina Foundation and Tordesil has Group for G.B.G. Mpos-doc scholarship and colleagues at ISC/UFF and Despacho 100 at La Rioja University for all the support offered during the postdoc period. We thank Mel M. M. Vianna for being so special.

\section{AUTHORS' CONTRIBUTIONS}

GBGM and FA contributed in the following aspects: Conception, planning, writing, analysis, interpretation, review, and writing of the final work. CMMV and PR contributed in the following aspects: analysis, interpretation, and review of the final work.

\section{CONFLICTS OF INTEREST}

The authors declare that there are no conflicts of interest concerning the content of the present study.

\section{FUNDING}

There are no disclosures of a declarable nature, financial of our editorial support.

\section{REFERENCES}

1. Castañeda-Hernández G, Szekanecz Z, Mysler E, Azevedo VF, Guzman R, Gutierrez M, et al. Biopharmaceuticals for rheumatic diseases in Latin America, Europe, Russia, and India: Innovators, biosimilars, and intended copies. Joint Bone Spine 2014;81:471-7.

2. Ministry of Health (Brazil), National Health Surveillance Agency (Anvisa). Biological Medicines for the Treatment of Rheumatoid Arthritis. Executive Secretary. Brazil: National Health Surveillance Agency; 2012.

3. Ministry of Health (Brazil), National Health Surveillance Agency. Statistical Yearbook of the Pharmaceutical Market. Brazil: National Health Surveillance Agency; 2018. Available from: http://www.portal.anvisa.gov.br/documents/374947/3413536/ Anu $\% \mathrm{C} 3 \%$ A1rio+Estat $\% \mathrm{C} 3 \%$ ADstico+do+Mercado+Farmac $\% \mathrm{C} 3 \% \mathrm{~A}$ Autico+-+2018/c24aacbf-4d0c-46a7-bb86-b92c170c83e1.

4. Zozaya N, Pérez-Camarero S, Martínez-Galdeano L. La Regulación y Financiación de los Medicamentos Biosimilares en la OCDE; 2017. Available from: http://www.weber.org.es/wp-content/uploads/2018/04/ La Regulacion y financiacion de los-biosimilares en la-OCDE weber.pdf.

5. González A, Ivanova Y, Zozaya N, Jiménez M, Hidalgo Á. The Introduction of Biosimilars in Spain. Estimation of Time for the National Health System. Madrid: Primera; 2017. p. 33. Available from: http://www.weber.org.es/wp-content/uploads/2018/04/Introducciónde-los-Biosimilares-en-España.pdf.

6. Malipatil NB, Haridas K, Prithvi SD. An overview of biosimilars. Asian J Pharm Clin Res 2015;8:23-7.

7. Bernal-Camargo DR, Gaitán-Bohórquez JC, León-Robayo ÉI. Biosimilar medicines in Colombia: An approach from the informed consumption. Rev Cienc Salud 2018;16:311-39.

8. Rovira J, Espín J, García L, Labry AO. The Impact of Biosimilars' Entry in the EU Market; 2011. Available from: http:/www.citeseerx.ist.psu. edu/viewdoc/citations;jsessionid=3D0987A4E2161E07E773A301041 639E4?doi=10.1.1.357.2218

9. Levenhagen K, Davies C, Perdomo M, Ryans K, Gilchrist L. Clinical Practice Guideline. New York: United Rheumatology; 2019.

10. Biosimilars Review and Report. Biosimilars, Biologics, FDA Policy and Approvals, Clinical Trials, and Specialty Pharmacy; 2019. Available from: https://www.biosimilarsrr.com/biosimilars-reviews-reports.

11. Drug Price Finder; 2019. Available from: https://www.drugs.com.

12. Mysler E, ÁlvarezAA, Hughes J, Flores-Murrieta FJ. Recommendations for the regulation of biosimilars and their implementation in Latin America. Generics Biosimilars Initiat J 2014;3:143-8.

13. Institute of Health Policy Studies. High Cost Drugs 403 for More Expensive Costs in Argentina than in the United Kingdom; 2016. Available from: http://www.ieps.com.ar/es/template. php?file=notas $/ 2016 / 08 / 16-08-31$ Medicamentos-de-alto-costo-403por-ciento.html.

14. Gomes EB, Rosseto R, Pinheiro L, Hasenclever L, Paranhos J. Development of biosimilars in Brazil. Front J Soc Technol Environ Sci 2016;5:31. Available from: http://www.revistas.unievangelica.edu.br/ index.php/fronteiras/article/view/1628.

15. Garcia R, Araujo DV. The regulation of biosimilars in Latin America. Curr Rheumatol Rep 2016;18:16.

16. Ministry of Health (Brazil), National Health Surveillance Agency. Consultation of the Medication Registry; 2019. Available from: http:// www.portal.anvisa.gov.br/consulta-produtos-registrados.

17. Ministry of Health, Health Assistance Secretariat (SAS). Clinical Protocol and Therapeutic Guidelines Rheumatoid Arthritis. Brazil: Ministry of Health; 2014. Available from: http://www.conitec.gov. br/images/Consultas/Relatorios/2019/Relatrio PCDT Artrite Reumatoide_CP21_2019.pdf.

18. Ministry of Health (Brazil), National Health Surveillance Agency (Anvisa). Consultation on the Price of Medicines Anvisa; 2019. Available from: http://www.portal.anvisa.gov.br/consulta-lista-depreco-de-medicamento.

19. Brazilian Institute of Geography and Statistics-IBGE. Prices and Costs. Available from: https://www.ibge.gov.br/estatisticas/economicas/ precos-e-custos.html. [Last accessed on 2019 Nov 08].

20. Brazilian Central Bank. Currency and Exchange Converter; 2019. Available from: https://www.bcb.gov.br/conversao.

21. Health Care Secretariat. Clinical Protocol and Therapeutic Guidelines for Rheumatoid Arthritis. Public Consultation No. 21. Brazil: Official Gazette (DOU); 2019. p. 27.

22. Araujo DV. Drug Prices in Latin America: Challenges for Setting the Reference Price in the Region. Case Study. Brazil: Mercosul; 2015. p. 86-90.

23. Vieira FS, Zucchi P. Price differences between generic and innovator medicines in Brazil. Rev Saude Publica 2006;40:444-9.

24. McCamish M, Woollett G. Worldwide experience with biosimilar development. MAbs 2011;3:212-20.

25. BOE Technology Group. Urgent Measures to Guarantee the Sustainability of the National Health System and Improve the Quality and Safety of its Services. Royal Decree Law 16/2012. BOE Num 98. Spain: BOE Technology Group; 2012. Available from: https://www. boe.es/eli/es/rdl/2012/04/20/16.

26. Calo-Fernández B, Martínez-Hurtado JL. Biosimilars: Company strategies to capture value from the biologics market. Pharmaceuticals (Basel) 2012;5:1393-408.

27. Shaik R, Muragundi PM. Evaluation of price disparity among generic medicines in India. Asian J Pharm Clin Res 2018;11:466-8.

28. Interfarma. Understanding Biological Medicines Interfarma Assoc da Indústria Farm Pesqui. Brazil: Interfarma; 2012. Available from: https:// www.interfarma.org.br/public/files/biblioteca/34-biologicos-site.pdf.

29. Blackstone EA, Fuhr JP. Innovation and competition: Will biosimilars succeed?: The creation of an FDA approval pathway for biosimilars is complex and fraught with hazard. Yes, innovation and market competition are at stake. But so are efficacy and patient safety. Biotechnol Healthe 2012;9:24-7.

30. Ministry of Health (Brazil), National Health Surveillance Agency (Anvisa). Generics and Similars Occupy $65 \%$ of the National Market Anvisa; 2019. Available from: http://www.portal.anvisa.gov.br/ noticias/-/asset_publisher/FXrpx9qY7FbU/content/genericos-esimilares-ocupam-65-do-mercado-nacional/219201. [Last accesssed on 2019 Nov 01]. 